\title{
Surgical treatment of early stage breast cancer in elderly: an international comparison
}

\author{
M. Kiderlen - E. Bastiaannet - P. M. Walsh $\cdot$ N. L. Keating S. Schrodi \\ J. Engel $\cdot$ W. van de Water $\cdot$ S. M. Ess $\cdot$ L. van Eycken $\cdot$ A. Miranda $\cdot$ \\ L. de Munck - C. J. H. van de Velde • A. J. M. de Craen • G. J. Liefers
}

Received: 16 November 2011/ Accepted: 18 November 2011/Published online: 27 November 2011

(C) The Author(s) 2011. This article is published with open access at Springerlink.com

\begin{abstract}
Over $40 \%$ of breast cancer patients are diagnosed above the age of 65 . Treatment of these elderly patients will probably vary over countries. The aim of this study was to make an international comparison (several European countries and the US) of surgical and radiation treatment for elderly women with early stage breast cancer. Survival comparisons were also made. Data were obtained from national or regional population-based registries in the Netherlands, Switzerland, Ireland, Belgium, Germany, and Portugal. For the US patients were selected from the Surveillance, Epidemiology, and End Results (SEER) database. Early stage breast cancer patients aged $\geq 65$ diagnosed between 1995 and 2005 were included. An international comparison was made for breast and axillary surgery, radiotherapy after breast conserving surgery (BCS), and relative or cause-specific survival. Overall,
\end{abstract}

M. Kiderlen · E. Bastiaannet · W. van de Water .

C. J. H. van de Velde · G. J. Liefers ( $₫)$

Department of Surgery, Leiden University Medical Center,

P.O. Box 9600, 2300, RC, Leiden, The Netherlands

e-mail: g.j.liefers@lumc.nl

E. Bastiaannet - W. van de Water - A. J. M. de Craen

Gerontology \& Geriatrics, Leiden University Medical Center,

Leiden, The Netherlands

P. M. Walsh

National Cancer Registry, Cork, Ireland

N. L. Keating

Brigham and Women's Hospital and Harvard Medical School, Boston, USA

S. Schrodi $\cdot$ J. Engel

Munich Cancer Registry (MCR) of the Munich Cancer Center

(MCC), Clinic Großhadern/IBE Ludwig-Maximilians-

University, Munich, Germany
204.885 patients were included. The proportion of patients not receiving any surgery increased with age in many countries; however, differences between countries were large. In most countries more than half of all elderly patients received breast conserving surgery (BCS), with the highest percentage in Switzerland. The proportion of elderly patients that received radiotherapy after BCS decreased with age in all countries. Moreover, in all countries the proportion of patients who do not receive axillary surgery increased with age. No large differences in survival between countries were recorded. International comparisons of surgical treatment for elderly women with early stage breast cancer are scarce. This study showed large international differences in treatment of elderly early stage breast cancer patients, with the most striking result the large proportion of elderly who did not undergo surgery

S. M. Ess

Cancer Registry of St. Gallen, Appenzell, Switzerland

L. van Eycken

National Cancer Registry of Belgium, Brussels, Belgium

\author{
A. Miranda \\ Cancer Registry of Southern Portugal (ROR-Sul), Lisboa, \\ Portugal \\ L. de Munck \\ Comprehensive Cancer Centre the Netherlands, Utrecht, \\ The Netherlands
}


at all. Despite large treatment differences, survival does not seem to be affected in a major way.

Keywords Breast cancer - Elderly - Surgery - Treatment · Survival $\cdot$ Population-based

\section{Introduction}

Breast cancer is the most frequently diagnosed cancer worldwide, accounting for $23 \%$ of all new cancer cases in women and $14 \%$ of all female cancer deaths in 2008 [1]. A high incidence of breast cancer is observed in women aged 65 years and older, comprising over $40 \%$ of all breast cancer patients in developed countries [2]. Given the aging population and constantly improving screening and diagnostic tools, the number of elderly patients with breast cancer is expected to grow in the coming decades [3].

Clinical trials indicate that the choice of mastectomy versus breast conserving surgery (BCS) followed by radiotherapy (RT) for early stage breast cancer does not affect overall mortality or breast cancer mortality [4, 5]. However, patients who receive BCS + RT have a small but significant increase in local recurrences. Elderly patients have been under-represented in breast cancer treatment trials, based on their age, comorbid diseases, and logistic barriers [2, 6]. Consequently it is questionable if trial results can be generalized to patients of all ages. Despite guideline recommendations, several observational studies from different countries show that with increasing age, treatment of early stage breast cancer more often consists of mastectomy; moreover, omission of RT after BCS increases with increasing age [3, 7-11]. In addition, older breast cancer patients are more likely than younger patients to not undergo breast surgery, even though mortality caused by breast surgery is shown to be low among elderly [12].

The different treatment approaches to elderly breast cancer patients could have consequences. Several observational studies showed worse overall, breast cancer specific, and disease-free survival for 'undertreated' elderly patients (not treated according to guidelines) [13, 14]. An international study comparing breast surgery among countries for patients participating in the Tamoxifen exemestane adjuvant multinational (TEAM) trial showed large differences in surgical treatment approach to early stage breast cancer in postmenopausal women [15]. The EUROCARE group recently published a population-based study on the surgical treatment of early stage breast cancer (T1N0M0) across Europe. They found considerable differences in the use of BCS followed by RT. Of all surgically treated patients across the participating countries, $55 \%$ received $\mathrm{BCS}+\mathrm{RT}$, with a range from $9 \%$ in Estonia to $78 \%$ in France [11]. However, none of these studies specifically compared treatment of the elderly patient with breast cancer. The aim of this study is to make an international comparison of breast and axillary surgery, and radiotherapy after breast conserving surgery in elderly patients with early stage breast cancer, and its possible influence on survival.

\section{Methods}

Patients

Women aged 65 and older, who were diagnosed with early stage breast cancer (T0-2, N0-1, M0) and recorded in population-based cancer registries in the Netherlands, Ireland, Switzerland, Belgium, Germany, Portugal, and the U.S. were included. From the population-based database of the Netherlands Cancer Registry, women diagnosed between 1995 and 2005 were selected. For the US, patients diagnosed between 1998 and 2007 were selected from the Surveillance, Epidemiology, and End Results (SEER) database covering $28 \%$ of the US population. In Switzerland, patients diagnosed between 2003 and 2005 were identified from seven population-based cancer registries (Geneva, Valais, Ticino, St Gallen-Appenzell, GrisonsGlarus, Basel city and countryside, and Zurich) covering $47 \%$ of the Swiss population. In Ireland, patients were selected from the national cancer registry between 1999 and 2007. In Belgium, patients diagnosed between 2001 and 2006 were selected from the national cancer registry. German patients diagnosed between 1995 and 2008 in the Munich region were selected. Finally, patients from the Portugal South regional cancer registry (ROR-Sul) were selected between 2006 and 2008. Patients with a diagnosis of breast cancer on death certificate or at autopsy only or with unknown treatment were excluded.

\section{Statistics}

Calculations of treatment percentages and survival were performed for each country and aggregated into tables for the comparison between countries. Patients were categorized in six age groups $(65-69,70-74,75-79,80-84$, $85-89$, and $\geq 90$ ) for the treatment analyses. Tumor stage was defined by combined TNM stage [16] (categorized as stage I, IIA, IIB), with clinical stage used when pathological stage was missing. Stage I includes T1N0 tumors, stage IIA T1N1, or T2N0 tumors and stage IIB contains T2N1 tumors (also T3N0 tumors but these were excluded from this study). Breast surgery was categorized as mastectomy, breast conserving surgery, or no surgery. Patients who received BCS first, but later received mastectomy, 
for any reason, were positioned in the mastectomy group. Receipt of radiation in addition to BCS was also assessed. Axillary surgery (either sentinel node biopsy or axillary lymph node sampling or dissection) was documented (yes/ no). Descriptive statistics were used, as only aggregated tables were compared, to assess the proportion of patients receiving each treatment; where possible percentages were compared using the $\chi^{2}$ test. A $P$ value of $<0.05$ was considered statistically significant.

Relative survival was calculated by the Ederer II method as the ratio of the survival observed among the cancer patients to the survival that would have been expected based on the corresponding (age, sex, and year of diagnosis) general population. National life tables for each country were used to estimate expected survival. In all countries and regions, vital status was established either directly from the patient's medical record or through linkage with the municipal or national population registries. The SEER database links with the National Death index, which also provided causes of death, and diseasespecific survival was calculated for patients treated in the US. Survival of Irish patients was mainly based on linkage to national mortality data, sometime supplemented with clinical information on date of death. For the survival analysis age was categorized as $65-74,75-84$, and $\geq 85$.

\section{Results}

Overall, 204.885 patients were included in the study. Characteristics of the populations are shown in Table 1. Age distribution was similar $(P=0.9)$ across participating countries. Stage distribution among European countries was comparable $(P=0.5)$, however, US patients more frequently had stage I disease $(P=0.06)$. Grade distribution was significantly different between the countries $(P<0.001)$.

\section{Breast surgery}

Figure 1 shows the proportions of patients who did not receive breast surgery in the several countries by age. The proportion of women not undergoing breast surgery varies among countries $(P<0.001)$ from $0.5 \%$ (MCR Germany) to $13.4 \%$ (Ireland). Overall, the proportion of patients who did not receive surgery increased with age. In the lowest age categories (65-69 and 70-74), proportions of patients without breast surgery were small $(<5 \%)$ in all countries (difference between countries were small but significant $P<0.001)$. As age increases, larger differences in the omission of breast surgery become apparent (again $P<0.001)$. In the US and Germany, in particular,

Table 1 Characteristics of the populations by country

\begin{tabular}{|c|c|c|c|c|c|c|c|c|c|c|c|c|c|c|c|}
\hline \multirow[t]{2}{*}{ Country } & \multicolumn{2}{|c|}{ Netherlands } & \multicolumn{2}{|c|}{ Belgium } & \multicolumn{2}{|c|}{ Switzerland } & \multicolumn{2}{|c|}{ Germany (MCR) } & \multicolumn{2}{|c|}{ Ireland } & \multicolumn{2}{|c|}{$\begin{array}{l}\text { Portugal } \\
\text { (ROR-Sul) }\end{array}$} & \multicolumn{2}{|l|}{ USA } & \multirow[t]{2}{*}{$P$ value } \\
\hline & Cases & $\%$ & Cases & $\%$ & Cases & $\%$ & Cases & $\%$ & Cases & $\%$ & Cases & $\%$ & Cases & $\%$ & \\
\hline \multicolumn{16}{|l|}{ Age } \\
\hline $65-69$ & 10,162 & 28.6 & 2,337 & 33.1 & 465 & 32.1 & 4,539 & 39.3 & 1,295 & 30.0 & 40 & 32.3 & 36,629 & 25.3 & 0.9 \\
\hline $70-74$ & 9,636 & 27.1 & 1,818 & 25.8 & 365 & 25.2 & 3,077 & 26.7 & 1,142 & 26.5 & 40 & 32.3 & 35,109 & 24.2 & \\
\hline $75-79$ & 6,982 & 19.6 & 1,503 & 21.3 & 273 & 18.8 & 2,322 & 20.1 & 901 & 20.9 & 23 & 18.5 & 33,279 & 23.0 & \\
\hline $80-84$ & 5,260 & 14.8 & 907 & 12.9 & 171 & 12.0 & 1,152 & 10.0 & 631 & 14.6 & 13 & 10.5 & 23,592 & 16.3 & \\
\hline $85-89$ & 2,687 & 7.6 & 340 & 4.8 & 100 & 7.2 & 376 & 3.3 & 271 & 6.3 & 7 & 5.6 & 11,678 & 8.1 & \\
\hline $90+$ & 853 & 2.4 & 153 & 2.2 & 50 & 3.5 & 73 & 0.6 & 72 & 1.7 & 1 & 0.8 & 4,561 & 3.1 & \\
\hline \multicolumn{16}{|l|}{ Stage } \\
\hline I & 15,894 & 44.7 & 3,331 & 47.2 & 657 & 46.0 & 5,471 & 47.4 & 1,476 & 34.2 & 55 & 44.4 & 90,402 & 62.4 & $0.06^{\mathrm{a}}$ \\
\hline IIA & 13,288 & 37.3 & 3,028 & 42.9 & 530 & 37.2 & 4,120 & 35.7 & 1,867 & 43.3 & 47 & 37.9 & 39,109 & 27.0 & \\
\hline $\mathrm{IIB}^{\mathrm{b}}$ & 6,398 & 18.0 & 699 & 9.9 & 237 & 16.6 & 1,948 & 16.9 & 969 & 22.5 & 22 & 17.7 & 15,337 & 10.6 & \\
\hline \multicolumn{16}{|l|}{ Grade } \\
\hline 1 & 5,316 & 14.9 & 1,193 & 16.9 & 314 & 22.0 & 1,503 & 13.0 & 476 & 11.0 & 17 & 13.7 & 36,182 & 25.0 & $<0.001$ \\
\hline 2 & 12,036 & 33.8 & 2,983 & 42.3 & 794 & 55.8 & 6,888 & 59.7 & 1,890 & 43.8 & 81 & 65.3 & 61,178 & 42.2 & \\
\hline $3 / 4$ & 7,383 & 20.8 & 2,259 & 32.0 & 253 & 17.7 & 2,842 & 24.6 & 1,188 & 27.6 & 11 & 8.9 & 35,409 & 24.5 & \\
\hline Missing & 10,845 & 30.5 & 623 & 8.8 & 63 & 4.4 & 306 & 2.7 & 758 & 17.6 & 15 & 12.1 & 12,079 & 8.3 & \\
\hline Total & 35,580 & 100 & 7,058 & 100 & 1424 & 100 & 11,539 & 100 & 4,312 & 100 & 124 & 100 & 144,848 & 100 & \\
\hline
\end{tabular}

MCR Munich cancer registry, ROR-Sul Portugal South Regional Cancer Registry

a $P=0.06$ including US, but $P=0.5$ among European countries only

b But excluding T3NOM0 
Fig. 1 Overall and age-specific percentages of the patients who did not receive breast surgery, by country
Fig. 2 Overall and age-specific percentage of patients that received breast conserving surgery (of all patients that received surgery), by country

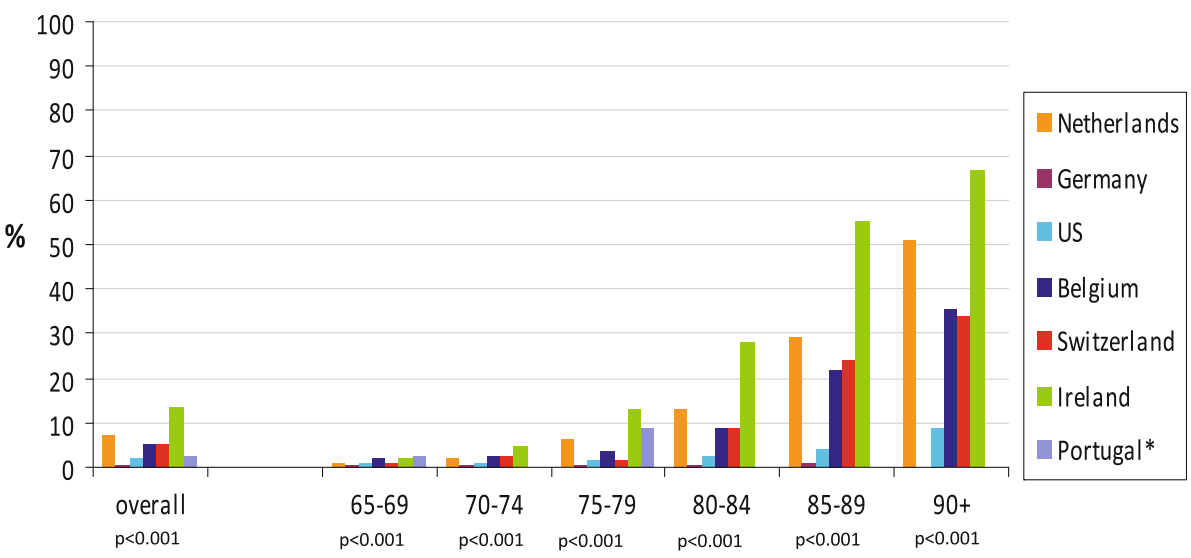

*Less than 50 patients in the selection

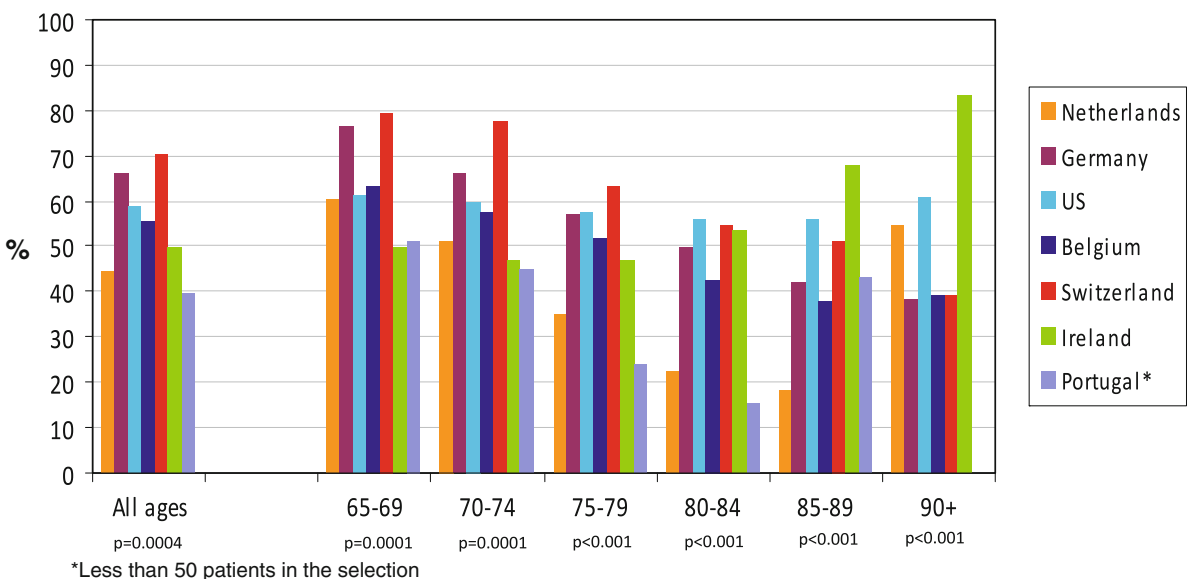

relatively few patients did not undergo breast surgery. However, in Ireland and the Netherlands more than half of patients aged 90 years and older had no breast surgery.

Figure 2 shows the proportion of the patients that received BCS (of all operated patients) in the countries by age. In most countries more than half of the included patients underwent BCS, except for the Netherlands, Ireland, and Portugal. The use of breast conserving procedures was highest in Switzerland (70\%). In all countries, except for the US and Ireland, the proportion of BCS decreased with age. In the US the proportion of BCS was relatively stable with age and in Ireland the use of BCS increased with age.

\section{Radiotherapy after breast conserving surgery}

Figure 3 shows the proportion of patients treated with BCS who received adjuvant RT. This proportion decreased substantially with age in all countries $(P<0.001)$, and also varied markedly between countries $(P=0.0005)$. The largest overall proportion of BCS followed by RT was observed in Belgium (85\%) and the lowest in Portugal $(59 \%)$ although the sample size was small for the latter.

\section{Axillary surgery}

Figure 4 shows proportions of all included patients who did not receive axillary surgery. The national cancer registry of Belgium could not provide this information and in the US, data on axillary staging were missing for $9.8 \%$ of patients. In all countries, the percentage of patients who did not undergo axillary surgery increased with age. However, there was major variation among countries $(P<0.001)$, from $1.4 \%$ (MCR Germany) to $22.6 \%$ (Ireland) overall.

\section{Survival}

Figure 5 shows the 5 -year survival after diagnosis by age and stage. For all ages combined, there were no major differences in survival between countries, with the highest relative survival for Ireland (99\%). Among stage I patients, survival was similar between countries in all age categories. For stage II, patients aged 65-74 years had a similar survival in all countries, but there were differences for patients aged $75-84$ and patients aged $\geq 85$, where survival was higher for patients in Germany (MCR) and Ireland. 
Fig. 3 Overall and age-specific percentages of patients that received BCS with radiotherapy (of all patients that received BCS), by country
Fig. 4 Overall and age-specific percentages of patients that received no axillary surgery, by country
Fig. 5 Relative survival (5years) for Stages I and II disease, by age and country

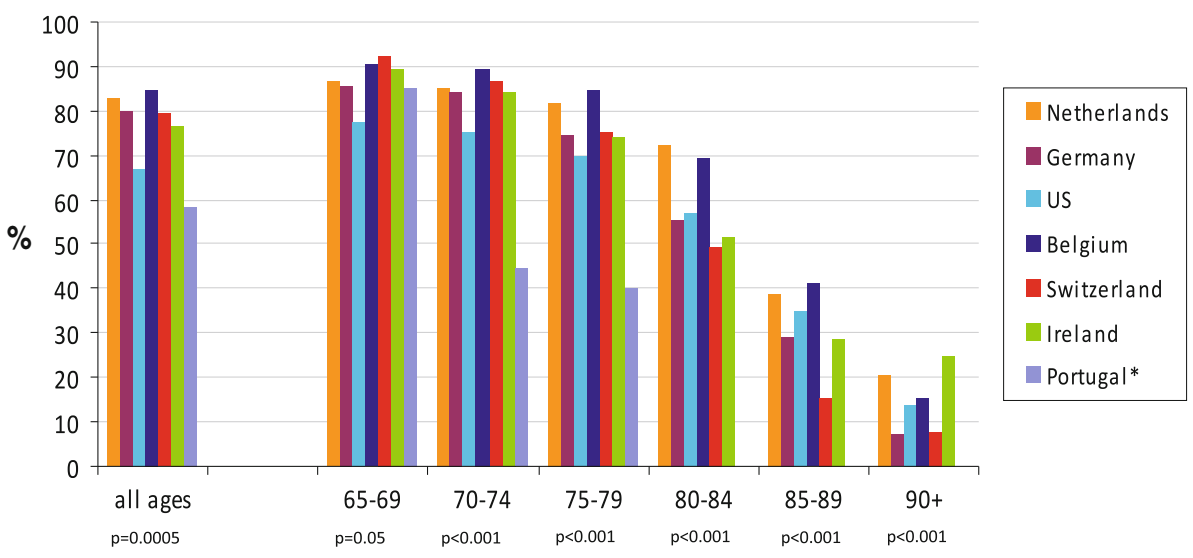

*Less than 50 patients in the selection
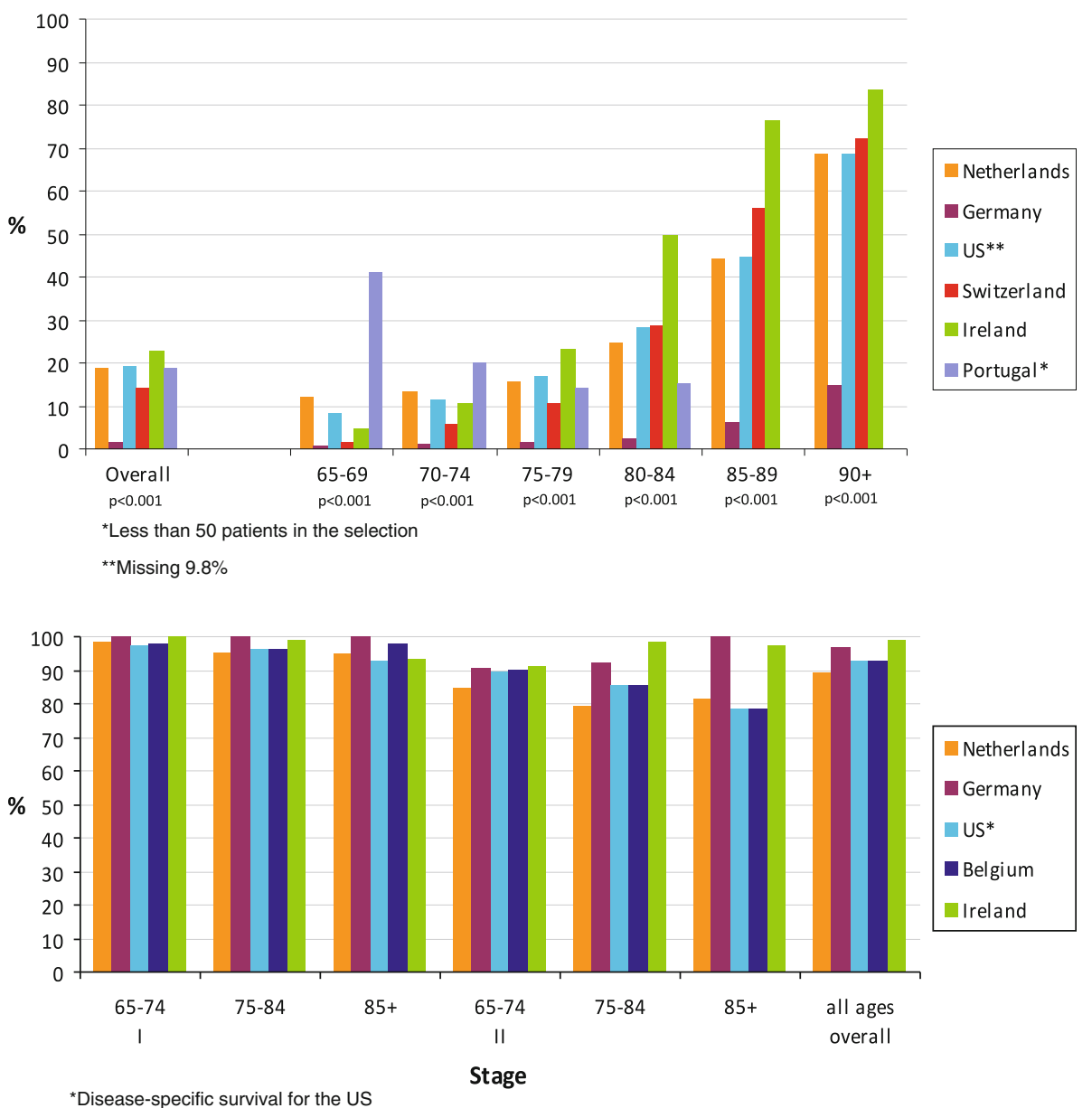

\section{Discussion}

Major findings of this study were the large differences in locoregional treatment across countries, especially in the proportion of elderly breast cancer patients receiving no breast surgery at all. However, despite substantial differences in breast cancer treatment, survival among countries was comparable. International comparisons of surgical treatment for elderly women with early stage breast cancer are scarce. In this study, we were able to make a comparison between several European countries and the US.

\section{Breast surgery}

The international differences in the percentage of elderly early stage breast cancer patients who did not undergo breast surgery are striking. Whereas, for example, in Ireland the percentage of patients aged $\geq 90$ who did not have 
surgery was $67 \%$, in the US only $8.8 \%$ had no surgery and in Germany all patients in this age category received breast surgery. The findings in the US are consistent with a recently published study from the US in which $98 \%$ of all $\mathrm{T} 1$ or $\mathrm{T} 2$ breast cancer patients aged $\geq 65$ years received at least some surgery [17]. International studies comparing the percentage of breast cancer patients who do not receive surgery are scarce. Most observational studies of survival excluded patients who did not have any surgical treatment, but the few retrospective studies that did include non-surgically treated patients showed poor overall and lower breast cancer-specific survival for these patients [13, 1719]. Many descriptive studies from different countries have also showed less extensive surgical treatment for elderly women with early stage breast cancer compared with younger patients $[2,3,7,11,12]$.

\section{Radiotherapy}

An overview of clinical trial data has shown that BCS should be followed by radiotherapy to achieve results comparable with mastectomy in terms of recurrence and survival [4]. In some elderly women BCS without radiation may be used to minimize potential treatment-related complications. However, the value of RT after BCS in elderly breast cancer patients is still subject of debate, since some studies suggest that radiation may be safely omitted for low-risk tumors in women over age 70 [20, 21]. This study shows that the proportion of women who received RT after BCS decreased with age. This trend was found in all participating countries, although specific proportions vary. Notable are the high percentages of elderly patients that received RT after BCS in Switzerland (79\%) and Germany (MCR 80\%). Possibly, for Switzerland, high accessibility of health services could partly explain this finding. For the selected German region (Munich), a previous study demonstrated that this specific region has a higher percentage of BCS for early stage breast cancer than five other regions in Germany, so this region may not be completely representative for the whole country [22]. Also interesting are the differences in breast surgery between the Netherlands and Ireland (both national databases). Both countries have a high proportion of patients that receive no breast surgery although it is higher in Ireland. The proportion of BCS decreases with age in the Netherlands but increases in Ireland; the proportion of adjuvant RT decreases with age in both countries. This remarkable difference in loco-regional therapy did not influence survival in any way. Information concerning loco-regional recurrences, not routinely collected by most cancer registries, could add some information to these comparisons and should be collected when possible in the future.
Axillary surgery

In all participating countries the proportion of women in whom axillary surgery was not performed increased with age, a finding consistent with another observational study [23]. The largest proportion was found in Ireland, directly followed by the US, Portugal and the Netherlands. Germany stands out on this topic; only $1.4 \%$ of the elderly breast cancer patients did not undergo any form of axillary surgery. Axillary staging is part of some guidelines, and these findings suggest that guideline adherence decreased with increasing age. However, several randomized and non-randomized studies showed very low rates of axillary recurrences and comparable disease-free and overall survival between clinical node-negative elderly breast cancer patients with and without axillary surgery [24, 25].

\section{Strengths and limitations}

One of the strengths of this comparison is the large number of patients and the population-based datasets that included all elderly patients. This facilitated comparison of treatment strategies in countries with similar health systems by using country as an instrumental variable.

A limitation of this study is that systemic treatment information was not available for all countries. However, available data indicate that rates of hormonal therapy (HT) were high: for example, among non-surgically treated patients, the proportion receiving HT was $85 \%$ in the Netherlands and $69 \%$ in Ireland. However, it is questionable if HT can replace surgery in elderly patients. Trials in which women aged $\geq 70$ were randomized to have surgery or HT do not show significant better overall survival for surgery compared to HT alone, although risk of recurrence is significantly larger when operable breast cancer in elderly is treated by tamoxifen alone [26, 27]. Another limitation of this study might be that information concerning the extent of "clear margins" after BCS was not available.

Another limitation of the study could be differences in data collection between the participating registries and the absence of national data for several countries (only the Netherlands, Belgium, and Ireland are national cancer registries). In countries with regional data, the regions may not be perfectly representative of the whole country. Also the small number of patients included for Portugal may not be representative and in some categories, numbers were insufficient to draw conclusions about treatment. Finally, the years of available data were not completely overlapping, and thus changes in treatment patterns over time could influence our findings. 


\section{Conclusions}

Despite the remarkable large differences in loco-regional treatment of early breast cancer, this study showed minimal differences in survival at 5 years between older breast cancer patients from seven Western countries. These findings raise the question whether more or less aggressive treatment of early stage breast cancer in elderly makes a difference. Future research should be focused on the best therapy for elderly women with respect to survival and quality of life. It may well be that the much criticized "less aggressive therapy" for elderly breast cancer patients does not harm patients with early stage disease, particularly women with comorbid illness that may otherwise limit their life expectancy. To properly investigate this, randomized controlled trials, specifically aimed at the elderly, is considered to give the best evidence. RCT's, however, are costly and time consuming en will not yield practice changing results within years from the start of such a trial. Furthermore, older patients are underrepresented in trials and no direct comparison of different approaches to the local regional treatment of early breast cancer in older women is available. International comparison of specific treatment protocols could serve as a good alternative to select 'best practices' and improve the risk/benefit ratio in the treatment of older breast cancer patients. This comparative effectiveness research can bridge the knowledge gap specifically in older cancer patient, who are by nature, heterogeneous in patient characteristics and treatment patterns [28].

Acknowledgments The authors would like to thank the Dutch Cancer Society (KWF 2007-3968), the Netherlands Cancer Registry (NCR) and Geriatric Oncology in the Netherlands (GeriOnNe).

\section{Conflicts of interest None.}

Open Access This article is distributed under the terms of the Creative Commons Attribution Noncommercial License which permits any noncommercial use, distribution, and reproduction in any medium, provided the original author(s) and source are credited.

\section{References}

1. Jemal A, Bray F, Center MM, Ferlay J, Ward E, Forman D (2011) Global cancer statistics. CA Cancer J Clin 61:69-90

2. Wildiers H, Kunkler I, Biganzoli L, Fracheboud J, Vlastos G, Bernard-Marty C, Hurria A, Extermann M, Girre V, Brain E, Audisio RA, Bartelink H, Barton M, Giordano SH, Muss H, Aapro M (2007) Management of breast cancer in elderly individuals: recommendations of the international society of geriatric oncology. Lancet Oncol 8:1101-1115

3. Louwman WJ, Vulto JC, Verhoeven RH, Nieuwenhuijzen GA, Coebergh JW, Voogd AC (2007) Clinical epidemiology of breast cancer in the elderly. Eur J Cancer 43:2242-2252
4. Early Breast Cancer Trialists' Collaborative Group (1995) Effects of radiotherapy and surgery in early breast cancer. An overview of the randomized trials. N Engl J Med 333:1444-1455

5. Clarke M, Collins R, Darby S, Davies C, Elphinstone P, Evans E, Godwin J, Gray R, Hicks C, James S, MacKinnon E, McGale P, McHugh T, Peto R, Taylor C, Wang Y (2005) Effects of radiotherapy and of differences in the extent of surgery for early breast cancer on local recurrence and 15-year survival: an overview of the randomised trials. Lancet 366:2087-2106

6. Hutchins LF, Unger JM, Crowley JJ, Coltman CA Jr, Albain KS (1999) Underrepresentation of patients 65 years of age or older in cancer-treatment trials. N Engl J Med 341:2061-2067

7. Bastiaannet E, Liefers GJ, de Craen AJ, Kuppen PJ, van de Water W, Portielje JE, van der Geest LG, Janssen-Heijnen ML, Dekkers OM, van de Velde CJ, Westendorp RG (2010) Breast cancer in elderly compared to younger patients in the Netherlands: stage at diagnosis, treatment and survival in 127, 805 unselected patients. Breast Cancer Res Treat 124:801-807

8. Keating NL, Landrum MB, Brooks JM, Chrischilles EA, Winer EP, Wright K, Volya R (2011) Outcomes following local therapy for early-stage breast cancer in non-trial populations. Breast Cancer Res Treat 125:803-813

9. Jagsi R, Abrahamse P, Morrow M, Hawley ST, Griggs JJ, Graff JJ, Hamilton AS, Katz SJ (2010) Patterns and correlates of adjuvant radiotherapy receipt after lumpectomy and after mastectomy for breast cancer. J Clin Oncol 28:2396-2403

10. Ess S, Joerger M, Frick H, Probst-Hensch N, Vlastos G, Rageth C, Lutolf U, Savidan A, Thurlimann B (2011) Predictors of stateof-the-art management of early breast cancer in Switzerland. Ann Oncol 22:618-624

11. Allemani C, Storm H, Voogd AC, Holli K, Izarzugaza I, TorrellaRamos A, Bielska-Lasota M, Aareleid T, Ardanaz E, Colonna M, Crocetti E, Danzon A, Federico M, Garau I, Grosclaude P, Hedelin G, Martinez-Garcia C, Peignaux K, Plesko I, Primic-Zakelj M, Rachtan J, Tagliabue G, Tumino R, Traina A, Tryggvadottir L, Vercelli M, Sant M (2010) Variation in 'standard care' for breast cancer across Europe: a EUROCARE-3 high resolution study. Eur J Cancer 46:1528-1536

12. Gennari R, Audisio RA (2008) Breast cancer in elderly women. Optimizing the treatment. Breast Cancer Res Treat 110:199-209

13. Bouchardy C, Rapiti E, Blagojevic S, Vlastos AT, Vlastos G (2007) Older female cancer patients: importance, causes, and consequences of under treatment. J Clin Oncol 25:1858-1869

14. Gajdos C, Tartter PI, Bleiweiss IJ, Lopchinsky RA, Bernstein JL (2001) The consequence of under treating breast cancer in the elderly. J Am Coll Surg 192:698-707

15. van Nes JG, Seynaeve C, Jones S, Markopoulos C, Putter H, van de Velde CJ, Hasenburg A, Rea DW, Vannetzel JM, Dirix L, Hozumi Y, Kerin MJ, Kieback DG, Meershoek-Klein Kranenbarg WM, Hille ET, Nortier JW (2010) Variations in locoregional therapy in postmenopausal patients with early breast cancer treated in different countries. Br J Surg 97:671-679

16. American Joint Committee on Cancer (1988) Manual for staging of cancer, 3rd edn. J.B. Lippincott Company, New York

17. Schonberg MA, Marcantonio ER, Li D, Silliman RA, Ngo L, McCarthy EP (2010) Breast cancer among the oldest old: tumor characteristics, treatment choices, and survival. J Clin Oncol 28:2038-2045

18. Bouchardy C, Rapiti E, Fioretta G, Laissue P, Neyroud-Caspar I, Schafer P, Kurtz J, Sappino AP, Vlastos G (2003) Under treatment strongly decreases prognosis of breast cancer in elderly women. J Clin Oncol 21:3580-3587

19. Van Leeuwen BL, Rosenkranz KM, Lei FL, Bedrosian I, Hartmann K, Hunt KK, Kuerer HM, Ross M, Singletary SE, Babiera GV (2010) The effect of under-treatment of breast cancer in 
women 80 years of age and older. Crit Rev Oncol Hematol 79(3):315-320

20. Fyles AW, McCready DR, Manchul LA, Trudeau ME, Merante P, Pintilie M, Weir LM, Olivotto IA (2004) Tamoxifen with or without breast irradiation in women 50 years of age or older with early breast cancer. N Engl J Med 351:963-970

21. Hughes KS, Schnaper LA, Berry D, Cirrincione C, McCormick B, Shank B, Wheeler J, Champion LA, Smith TJ, Smith BL, Shapiro C, Muss HB, Winer E, Hudis C, Wood W, Sugarbaker D, Henderson IC, Norton L (2004) Lumpectomy plus tamoxifen with or without irradiation in women 70 years of age or older with early breast cancer. N Engl J Med 351:971-977

22. Engel J, Nagel G, Breuer E, Meisner C, Albert US, Strelocke K, Sauer H, Katenkamp D, Mittermayer C, Heidemann E, Schulz KD, Kunath H, Lorenz W, Holzel D (2002) Primary breast cancer therapy in six regions of Germany. Eur J Cancer 38:578-585

23. Rescigno J, Zampell JC, Axelrod D (2009) Patterns of axillary surgical care for breast cancer in the era of sentinel lymph node biopsy. Ann Surg Oncol 16:687-696

24. Gerber B, Heintze K, Stubert J, Dieterich M, Hartmann S, Stachs A, Reimer T (2011) Axillary lymph node dissection in early stage invasive breast cancer: is it still standard today? Breast Cancer Res Treat 128(3):613-624
25. Martelli G, Miceli R, Daidone MG, Vetrella G, Cerrotta AM, Piromalli D, Agresti R (2011) Axillary dissection versus no axillary dissection in elderly patients with breast cancer and no palpable axillary nodes: results after 15 years of follow-up. Ann Surg Oncol 18:125-133

26. Chakrabarti J, Kenny FS, Syed BM, Robertson JF, Blamey RW, Cheung KL (2010) A randomised trial of mastectomy only versus tamoxifen for treating elderly patients with operable primary breast cancer-final results at 20-year follow-up. Crit Rev Oncol Hematol 78(3):260-264

27. Hind D, Wyld L, Beverley CB, Reed MW (2006) Surgery versus primary endocrine therapy for operable primary breast cancer in elderly women (70 years plus). Cochrane Database Syst Rev CD004272. doi:10.1002/14651858.CD004272.pub2

28. Hsiao FY, Mullins CD, Onukwugha E, Pandya N, Hanna N (2011) Comparative effectiveness of different chemotherapeutic regimens on survival of people aged 66 and older with stage III colon cancer: a "Real World" analysis using surveillance, epidemiology, and end results-medicare data. J Am Geriatr Soc. doi: 10.1111/j.1532-5415.2011.03501.x. 